\title{
Landscape ecological risk assessment and spatiotemporal change analysis in Yonghe County
}

\author{
Jixuan Yan ${ }^{1,2}$, Guang $\mathrm{Li}^{2 *}$, Haiyan Wang ${ }^{2}$, Meihua Zhang ${ }^{1}$, Dongyuan Sun $^{1}$ and Xia Kang ${ }^{1}$ \\ ${ }^{1}$ College of Water Resources and Hydropower Engineering, Gansu Agricultural University, Lanzhou 730070, China \\ ${ }^{2}$ College of Forestry, Gansu Agricultural University, Lanzhou 730070, China
}

\begin{abstract}
On the basis of land use data, combined with ArcGIS and fragstats4.2, the landscape ecological risk spatial mode and process feature of Yonghe county from 1980 to 2018 were analyzed. The results showed that: (1) from 1980 to 2018, the landscape pattern of Yonghe county changed obviously, the area of arable land and holt decreased, while the area of grassland, water and buildings grow a number. The conversion area between arable land and grassland is the largest. In Yonghe County, the fragmentation degree of landscape is on the rise, and the separation degree is also on the rise. The overall dominance of construction land is the largest, and the dominance of grassland is the smallest. (2) The landscape ecological risk level gradually subsided, the area of middle risk area decreased, and moderate risk areas are falling. From the spatial distribution analysis, the risk types of Yonghe County subsided from southeast to northwest. The high-risk areas were principally scattered in sangbi town and Jiaokou township. The main landscape type in this area was grassland, which was easily disturbed by human activities; the low-risk areas were principally scattered in Potou Township in the north and Yonghe County in the middle of the study area, and Woodland and buildings are the main landscape types land have strong anti-interference ability and low risk value.
\end{abstract}

\section{Introduction}

With the influence of the change of environmental management objectives and concepts, landscape ecological risk evaluate has gradually become one of the hot spots in the field of geography, ecology and other disciplines. With development of risk evaluate, asses the scale is constantly expanding, from the initial ecosystem to the present landscape pattern and regional ecological security [1].

In recent years, a large number of domestic scholars use different index construction methods to study regional ecological risk evaluate[2]. For example, Xu LAN, Zhou Rujia and other scholars have evaluated the regional ecological risk from landscape structure change, and carried out spatial autocorrelation analysis of regional ecological risk to study the spatial characteristics of ecological risk[3]. Therefore, this paper takes Yonghe County of Shanxi Province as an example to evaluate the landscape ecological risk of the water and soil conservation function ecological protection area in time series, so as to understand the landscape ecological risk status of the soil and water conservation area, so as to provide reference basis for land ecological security and regional ecological risk prevention and control in the study area.

\section{Research area}

Yonghe County, subordinate to Linfen City, Shanxi Province, is located in the south of Luliang mountains and the East Bank of Shanxi Shaanxi Grand Canyon inter reaches of the Yellow River, with a overall area of 1212 square kilometers (Fig. 1). It is a part of the Western Shanxi Plateau, with overlapping hills and ridges, vertical and horizontal gullies, serious soil erosion and extremely fragile ecological environment.

\section{Data origin and research methods}

\subsection{Data origin and processing}

This paper uses the land use data of resource and environment center of Chinese Academy of Sciences as the data source, which are respectively in 1980, 2000 and 2018 , with a resolution of $30 \mathrm{~m} \times 30 \mathrm{~m}$. Yonghe county is divided into five categories of arable land, woodland, meadow, water area and construction land as risk receptors.

*corresponding author's e-mail:lig@gsau.edu.cn 


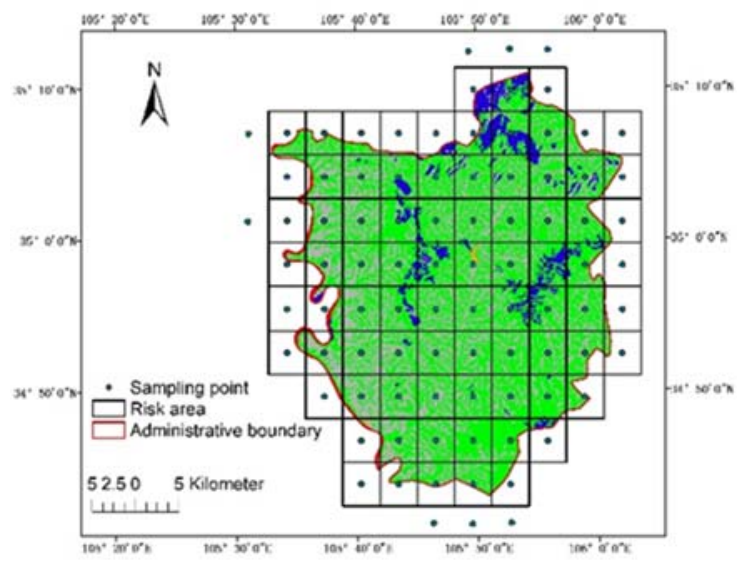

Fig. 1. Caption of the Figure 1. Below the figure.

\subsection{Division of risk area}

In order to collect the ecological risk evaluate unit and display the ecological risk index in the study area, arcgis 10.5 was used to grid Yonghe county.This paper adopts a $1 \mathrm{~km} \times 1 \mathrm{~km}$ square grid for equal interval sampling, and divides 82 evaluation units (Fig. 1). Ecological risk index of each risk area is calculated by using the ecological risk evaluate model, and the ecological risk value is assigned as the value of the sample plot center point, as the sample of spatial interpolation analysis.

\subsection{Research method}

\subsubsection{Landscape disturbance index $\left(E_{i}\right)$.}

The index of landscape disturbance degree indicates the level of external disturbance to various landscapes[5]. The expression is as follows: $E_{i}=a C_{i}+b N_{i}+c D_{i}$

Where $C_{i}$ is landscape fragmentation index; $N_{i}$ is landscape separation index; $D_{i}$ is landscape separation index. and $\mathrm{a}, \mathrm{b}$ and $\mathrm{c}$ are the corresponding weights. Referring to the existing achievements, the indexes are 0.5 , 0.3 and 0.2 respectively.

\subsubsection{Landscape fragility index[6] $\left(F_{i}\right)$.}

The higher the value, the more unstable the ecosystem is. According to the existing results, the six landscape types were classified according to the ability of resisting external influence: water area $=5$, unused land $=6$, arable land $=4$, woodland $=2$, meadow $=3$, buildings $=1$, and the landscape vulnerability index was calculated by normalization.

\subsubsection{Landscape ecological loss degree $\left(R_{i}\right)$.}

The landscape index method can clearly reflect the dynamic changes of landscape pattern by quantifying landscape indicators [7] . It reflects the loss degree of different landscapes when they are affected by the outside world. The formula is as follows: $R_{i}=E_{i} \times F_{i}$

Where $E_{i}$ is landscape disturbance index; $F_{i}$ is Landscape fragility index.

\subsubsection{Ecological risk index $\left(E R I_{i}\right)$.}

The expression is as follows: $E R I_{i}=\sum_{i}^{N} \frac{A_{k i}}{A_{k}} R_{i}$, Where $A_{k i}$ is the acreage for landscape $\mathrm{i}$ in the $\mathrm{k}$ sampling area; $\mathrm{n}$ is the number of landscape types;and $A_{k}$ is the total acreage in the $\mathrm{k}$ sample [8].

\subsubsection{Spatial autocorrelation analysis.}

In the software arcgis10.5, the landscape ecological hazard value is assigned to the center points of 82 risk areas, and the data is optimized by using the semi variance variation function in statistics, and the ecological risk map is generated by using Kriging interpolation. In order to better identify the landscape ecological hazard changes in each period $[9,10]$. the risk value is classified into five ecological hazard levels, very high ecological wind Risk areas (ERI $>0.05)$, high ecological risk areas $(0.035 \leqslant$ ERI $<0.05)$, moderate ecological hazard areas $(0.020 \leqslant$ ERI $<0.035)$, low ecological risk areas $(0.014 \leqslant$ ERI $<$ $0.020)$, very low ecological hazard areas $($ ERI $<0.014)$.

\section{Results}

\subsection{Land use change in Yonghe County}

Based on ArcGIS, three land use maps (Figure 2) and transfer matrix of 1980-2000, 2000-2018 and 2000-2018 are obtained. In recent 40 years, the grow in number land types of Yonghe County include meadow, construction land and water area, which increase by $10.92 \mathrm{~km}^{2}$ and 2.17 $\mathrm{km}^{2}$ and 0.74 respectively, and the reduced land types are arable land and forest land, which are reduced by $11.3 \mathrm{~km}^{2}$ and $2.6 \mathrm{~km}^{2}$ respectively.
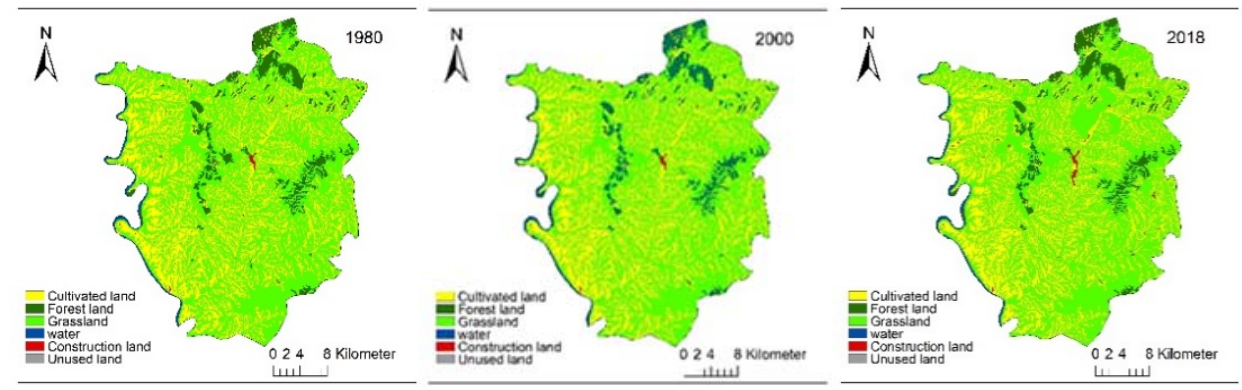

Figure 2. Land use change map in 1980, 2000 and 2018 
Table 1.Land use change matrix from 1980 to $2000 . \mathrm{km}^{2}$

\begin{tabular}{|c|c|c|c|c|c|c|}
\hline & Cultivatedland & forestland & grassland & Water & constructionland & 2000Total \\
\hline Cultivatedland & 401.18 & 0.13 & 1.06 & 0.00 & 0.00 & 402.37 \\
\hline forestland & 0.01 & 74.49 & 0.03 & 0.00 & 0.00 & 74.52 \\
\hline grassland & 0.28 & 2.77 & 723.14 & 0.00 & 0.00 & 726.20 \\
\hline Water & 0.00 & 0.00 & 0.00 & 13.36 & 0.00 & 13.37 \\
\hline constructionland & 0.00 & 0.00 & 0.00 & 0.00 & 1.79 & 1.79 \\
\hline 1980Total & 401.48 & 77.39 & 724.23 & 13.37 & 1.79 & 0.00 \\
\hline
\end{tabular}

Table 2. Land use change matrix from 2000 to $2018 . \mathrm{Km}^{2}$

\begin{tabular}{|c|c|c|c|c|c|c|}
\hline & Cultivatedland & forestland & grassland & Water & constructionland & 2018Total \\
\hline Cultivatedland & 342.81 & 0.76 & 46.37 & 0.09 & 0.11 & 390.17 \\
\hline forestland & 1.07 & 70.27 & 3.33 & 0.02 & 0.02 & 74.72 \\
\hline grassland & 56.75 & 3.39 & 674.86 & 0.10 & 0.06 & 735.16 \\
\hline Water & 0.11 & 0.09 & 0.86 & 13.04 & 0.02 & 14.11 \\
\hline constructionland & 1.61 & 0.01 & 0.77 & 0.00 & 1.58 & 3.96 \\
\hline 2000Total & 402.37 & 74.52 & 726.20 & 13.37 & 1.79 & 0.00 \\
\hline
\end{tabular}

Table 3. Land use change matrix from 1980 to 2018 . $\mathrm{Km}^{2}$

\begin{tabular}{|c|c|c|c|c|c|c|}
\hline & Cultivatedland & forestland & grassland & Water & constructionland & 2018Total \\
\hline Cultivatedland & 342.15 & 0.86 & 46.95 & 0.09 & 0.11 & 390.17 \\
\hline forestland & 1.07 & 70.29 & 3.33 & 0.02 & 0.02 & 74.72 \\
\hline grassland & 56.53 & 6.14 & 672.32 & 0.10 & 0.06 & 735.16 \\
\hline Water & 0.11 & 0.09 & 0.85 & 13.04 & 0.02 & 14.11 \\
\hline constructionland & 1.61 & 0.01 & 0.76 & 0.00 & 1.58 & 3.96 \\
\hline 1980Total & 401.48 & 77.39 & 724.23 & 13.37 & 1.79 & 0.00 \\
\hline
\end{tabular}

From the perspective of time, the changes of land use types from 1980 to 2000 were relatively small, including arable land, meadow and buildings, which increased by $0.89 \mathrm{~km}^{2}, 1.96 \mathrm{~km}^{2}$ and $0.0009 \mathrm{~km}^{2}$, respectively; the land use type with relatively large reduction was woodland, with a decrease of $2.86 \mathrm{~km}^{2}$, and the water body was relatively stable, with a decrease of $0.0018 \mathrm{~km}^{2}$ (Table 1).

However, from 2000 to 2018 , the change of land use types was relatively large, meadow and construction land a grow in number by $8.96 \mathrm{~km}^{2}$ and $2.17 \mathrm{~km}^{2}$, arable land reduced by $12.19 \mathrm{~km}^{2}$, and the increased area of forest land and water body was smaller, $0.20 \mathrm{~km}^{2}$ and $0.74 \mathrm{~km}^{2}$, respectively (Table 2). During the study period, the landscape pattern of Yonghe county was greatly affected by the rapid development of urbanization, especially during the period from 2000 to 2018, Buildings is on the increase trend, and the expansion of construction land and water area is inseparable from the occupation of arable land and meadow,which was also the reason for the large reduction of arable land and meadow area. In terms of the types of land use transferred in and transferred out, the area of grassland, water area and buildings has continued to increase in recent 40 years. The main supply sources of water area are meadow, arable land and a small amount of woodland. Among them, meadow is transferred $0.1 \mathrm{~km}^{2}$ to water area, and arable land is $0.09 \mathrm{~km}^{2}$ to water area; the main supply source of construction land is arable land, with a total of $0.11 \mathrm{~km}^{2}$ to buildings ( Table 3 ).

\subsection{Analysis of landscape index}

Using the software fragstats 4.2 and excel, referring to the formula listed, the landscape pattern index of five types of landscape in the study area in 1980, 2000 and 2018 was calculated (Table 4).

Table 4. Landscape pattern index of Yonghe County

\begin{tabular}{|c|c|c|c|c|c|c|c|c|c|}
\hline Landscape type & Time & $\begin{array}{c}\text { Area } \\
/ \mathrm{km}^{2}\end{array}$ & $\begin{array}{c}\text { Numb } \\
\text { er }\end{array}$ & $\begin{array}{c}\text { Fragme } \\
\text { ntation } \\
\text { index }\end{array}$ & $\begin{array}{c}\text { Abrupti } \\
\text { on } \\
\text { index }\end{array}$ & $\begin{array}{c}\text { Predom } \\
\text { inance } \\
\text { index }\end{array}$ & $\begin{array}{c}\text { Obstruc } \\
\text { tion } \\
\text { index }\end{array}$ & $\begin{array}{c}\text { Fragil } \\
\text { ity } \\
\text { index }\end{array}$ & $\begin{array}{c}\text { Damnif } \\
\text { y index }\end{array}$ \\
\hline Cultivated land & 1980 & 401.44 & 1232 & 3.07 & 1.53 & 2.50 & 2.49 & 0.19 & 0.47 \\
\hline & 2000 & 402.33 & 1235 & 3.07 & 1.52 & 2.50 & 2.49 & 0.19 & 0.47 \\
\hline
\end{tabular}




\begin{tabular}{|c|c|c|c|c|c|c|c|c|c|}
\hline & 2018 & 390.14 & 1252 & 3.21 & 1.58 & 2.49 & 2.58 & 0.19 & 0.49 \\
\hline Woodland & 1980 & 77.38 & 117 & 1.51 & 2.44 & 2.89 & 2.07 & 0.10 & 0.20 \\
\hline & 2000 & 74.51 & 113 & 1.52 & 2.49 & 2.40 & 1.99 & 0.10 & 0.19 \\
\hline & 2018 & 74.72 & 121 & 1.62 & 2.57 & 2.40 & 2.06 & 0.10 & 0.20 \\
\hline Grassland & 1980 & 724.17 & 135 & 0.19 & 0.28 & 2.30 & 0.64 & 0.14 & 0.09 \\
\hline & 2000 & 726.14 & 138 & 0.19 & 0.28 & 2.30 & 0.64 & 0.14 & 0.09 \\
\hline & 2018 & 735.10 & 157 & 0.21 & 0.30 & 2.28 & 0.65 & 0.14 & 0.09 \\
\hline Water area & 1980 & 13.37 & 21 & 1.57 & 5.98 & 2.88 & 3.16 & 0.24 & 0.75 \\
\hline & 2000 & 13.37 & 23 & 1.72 & 6.26 & 2.88 & 3.32 & 0.24 & 0.79 \\
\hline Construction land & 2018 & 14.11 & 14 & 0.99 & 4.63 & 2.85 & 2.45 & 0.24 & 0.58 \\
\hline & 2000 & 1.79 & 18 & 10.08 & 41.45 & 6.78 & 18.83 & 0.05 & 0.90 \\
\hline & 2018 & 3.96 & 30 & 7.57 & 24.11 & 4.02 & 11.82 & 0.05 & 0.56 \\
\hline
\end{tabular}

From the results, it can be seen that with the increase of meadow and water area, the dominance degree is also rising. During the study period, the loss degree of arable land and grassland changed the most and showed an upward trend. The reason is that the land type dominated by plateau in Yonghe county has overlapping hills and ridges and ravines. Arable land and meadow are principally distributed, while the meadow area decreases, its fragmentation also increases. In the study area, the meadow vulnerability is relatively high, which leads to an upward trend of grassland loss; while the water area gradually reduces, leading to the decline of its fragmentation, at the same time, the vulnerability of water area is also relatively high, which leads to the increase of its loss degree.

\subsection{Ecological risk changes}

The spatial difference analysis of landscape ecological hazard in Yonghe county shows that the spatial arrangement of landscape ecological hazard in Yonghe county has obvious location and heterogeneity characteristics (Fig. 3). The risk type principally scattered in the northern part of the paper is low ecological hazard, with obvious spatial aggregation. This area is a contiguous forest land with obvious landscape advantages. Over the years, it has formed a relatively stable landscape structure with low landscape fragmentation and separation; The areas with low ecological risk are principally scattered in scattered in Yonghe county with complete landscape structure and strong anti-interference ability; the middle ecological risk is principally scattered in scattered in Yonghe county To be scattered in the area around the county seat of the study area, there are more fragmented woodlands and meadows in this area, which have poor stability and relatively fragile ecosystem; the higher ecological hazard is principally scattered in scattered in the southern part, including sangbi Town, Gedi Township and Jiaokou Township, where the terrain is low and there is a large range of meadow, and the human disturbance intensity is large; the ecological risk is high The area is principally located in the southwest of China, with more fragmented arable land and the highest potential ecological hazard of landscape.
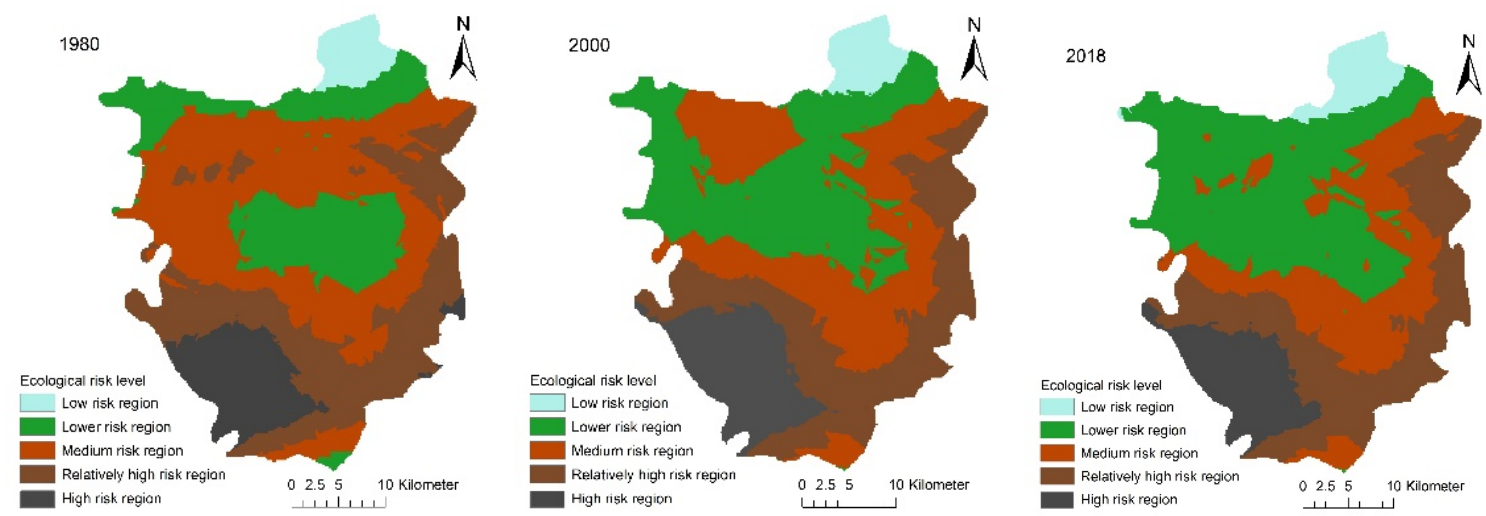

Figure 3. Landscape ecological risk distribution in 1980, 2000 and 2018

\section{Discussion}

From the core connotation of landscape ecological hazard, the main risk sources of landscape ecological hazard are 
the increase of man-made landscape and the decrease of natural landscape. Human activities change the pattern and composition structure of surface ecosystem, thus affecting the service function and spatial distribution of ecosystem, leading to the imbalance of ecosystem and the increase of ecological risk. The pattern and evolution characteristics of landscape ecological hazard not only directly reflect the characteristics of ecological environment, but also the ability of ecosystem to resist external interference and disturbance. In order to clearly express the spatial distribution characteristics of landscape ecological hazard degree in Yonghe county. The results show that:

From 2010 to 2015, the landscape pattern of Yonghe county has changed obviously, the area of woodland and arable land subsided significantly, meadow, water body and buildings expanded significantly, and the expansion area principally came from the transformation of arable land and grassland area. From 1980 to 2018, the landscape fragmentation with a grow in number as a whole. In 1980, the fragmentation degree of buildings was the highest, followed by arable land, woodland, water area and meadow. After nearly 40 years of change, except for buildings and water area, the fragmentation of other landscape types has grow in number. From 1980 to 2018, the level of separation of Yonghe county also changed significantly. Except for the water area and buildings, the level of separation of other landscape types growed to varying degrees. From 1980 to 2018, the overall landscape dominance of Yonghe county did not change much. The landscape dominance of buildings was the largest, followed by woodland and water area, and farmland and meadow were the smallest.

In 2015, the area of moderate risk area reduced significantly, while the area of mild risk area increased, and the area of high risk area subsided importantly.

In view of the analysis of spatial arrangement, the landscape risk types of Yonghe county showed a decreasing trend from south to north. The area with high risk is principally arable land, which has mostly rural residential areas, and is vulnerable to human activities, and the ecological environment is fragile; the northwest is principally the type of low-risk areas; most of the low-risk areas are in the north of the study area, and the main landscape type is woodland, with low degree of fragmentation, strong anti-interference ability and lowest risk value.

\section{Acknowledgment}

Fund Project: Gansu Provincial Special Project(SSCZZ20160909)

\section{References}

1. Xu Yan, Gao Junfeng, Gao Yongnian. Landscape ecological risk assessment of Taihu Lake area based on dynamic change of land use. Lakes Science ,2011,23(4):642-648.

2. Gong Jie, Zhao Caixia, Xie Yuchu, Gao Yanjing.
Ecological risk assessment and management of Bailong River Basin in Gansu Province based on landscape pattern. Journal of Applied Ecology 25(7):2041-2048.

3. Gao Bin, Li Xiaoyu, Li Zhigang, Chen Wei, he Xingyuan, Qi Shanzhong. Ecological risk analysis of Jinzhou Bay Coastal Economic Development Zone based on landscape pattern. Journal of Ecology ,2011,31(12):3441-3450.

4. Gao Yongnian, Gao Junfeng, Xu Yan. Landscape ecological risk effect of land use change in water ecological function area of Taihu Lake Basin. Journal of Natural Resources,2010,25(7):1088-1096.

5. Gao Bin, Li Xiaoyu, Li Zhigang, et al. Ecological Risk Analysis of Jinzhou Bay Coastal Economic Development Zone Based on Landscape Pattern [J]. Ecologica Sinica ,2011,31(12):3441-3450

6. Zhang Yue, Zhang Fei, Wang Juan, et al. Study on Ecological Risk Assessment and Prediction of Lake Abby Region Based on LUCC [J].]; and China Environmental Science 36(11):3465-3474.

7. Wang J, Cui B S, Liu J, et al. The effect of land use and its change on ecological risk in the Lancang River watershed of Yunnan Province at the landscape scale[J]. Acta Scientiae Circumstantiae, 2008, 28(2): 269-277.

8. Zhang Y, Zhang F, Zhou M, et al. Landscape ecological risk assessment and its spatiotemporal variations in Ebinur Lake region of inland arid area $[\mathrm{J}]$. Chinese Journal of Applied Ecology, 2016, 27(1): 233-242.

9. Tian Y, Li B, Wang S. Study on landscape ecological risk of the coastal areas of Jiangsu Province[J]. Research of Soil and Water Conservation, 2015, 22(1): 241-245, 251.

10. Xu Y, Gao J F, Gao Y N. Landscape ecological risk assessment in the Taihu region based on land use change[J]. Journal of Lake Sciences, 2011, 23(4): 642-648. 